\title{
A hora da estrela: a palavra como fomento da tradição literária
}

\author{
Eliane Maria de Oliveira Giacon \\ Doutoranda - Unesp / Professora - UEMS
}

\begin{abstract}
Resumo:
Para arquitetar Macabéa como uma construção narrativa, foi necessário a Clarice Lispector retroceder um instante anterior ao ato de criação. Àquela luz, que dá o início à vida. E como dar início à vida de uma personagem mulher, sem passar pelo momento de sua concepção e de sua gestação. É aí que reside a fórmula encontrada por Clarice Lispector, pois procurar respostas é um exercício constante de encontrar-se e encontrar a origem de todas as coisas, logo a arquitetura dessa nordestina é antes de tudo a planta que desenha linhas congruentes, que se aproximam da tradição literária brasileira da relação entre crime, pecado e monstruosidade, fundada por Machado de Assis.
\end{abstract}

Palavras-chave: Tradição; símbolos; crime

Poetas e prosadores convivem num universo no qual a maior preocupação é a criatividade, seja ela de ordem formal ou temática. Razão essa que impulsionou a Literatura ao estado de ciência e filosofia. Ciência pelas diferentes formas de produção e experimentação poéticas realizadas, na sua grande maioria, no século 20, e ao mesmo filosófica, quando essa produção indaga além dos limites eventuais da escrita e aprofunda-se na busca de respostas às indagações mais ínfimas do ser humano, entre elas a sua origem. E é nessa origem que se esboça a arquitetura de uma mulher.

Ao procurar o primeiro momento quando "Uma molécula disse sim a outra molécula e nasceu a vida"1 ou até a pré-história desse instante, no qual o ato de criar é a própria criatura e qualquer movimento, no cosmo, por mais simples que seja resulta na arquitetura de todas as coisas, Clarice Lispector tenta desvendar, em seus textos, o intervalo infinitesimal, no qual, dentro do nada, uma centelha de luz dimensiona a projeção dessa mulher.

\footnotetext{
${ }^{1}$ LISPECTOR. A hora da estrela, p. 1.
} 
Este instante, no início da vida também situa a projeção geométrica da mulher. Uma mulher que busca resolver-se ao criar e cria-se para resolver os enigmas da vida. E sendo mulher Clarice Lispector pode criar uma literatura que remove as poeiras ancestrais do cosmo de cada ser, criando um texto que se lê e lê os outros, pois "O ato de criar em Lispector é imperioso. ${ }^{2}$ De tal forma que a vida e a obra dessa autora estão entrelaçadas mesmo quando ela tenta de todas as formas se eximir de qualquer essência do ser mulher. Um exemplo ocorre com o narrador de $A$ hora da estrela, instituído para narrar a história de uma nordestina de nome Macabéa e o ato de criar. Nesse caso ela prefere "Um outro escritor, sim, mas teria que ser homem porque escritora mulher pode lacrimejar piegas." ${ }^{3}$ Eximirse de ser uma mulher para falar de outra mulher foi a princípio até uma forma de desvincular a autora de sua obra, contudo Lispector se traí ao falar do ato de criar, na voz de Rodrigo S. M. "Escrevo por não ter nada a fazer no mundo: sobrei e não há lugar para mim na terra dos homens. ${ }^{\prime 4}$ Esse trecho lembra a seguinte frase da escritora (...) "eu escrevo e assim me livro de mim $(\ldots)^{\prime} .{ }^{5} \mathrm{O}$ não ter nada a fazer e o se livrar de si mesmo é o que move toda a narrativa lispectiana. Isso não no sentido de desprezo pela escrita ou pelo leitor, mas para desprender-se do que a cerca, e se colocar, num estagio à frente do momento da criação, no qual o que foi criado e o criador não mais são responsáveis um pelo outro. O leitor sim poderá unir obra e autora, sem receio de fazer uma análise deslocada de teoria literária atual.

Arquitetar Macabéa como uma construção narrativa, foi necessário a Clarice Lispector retroceder um instante anterior ao ato de criação. Àquela luz, que dá o início à vida. E como dar início à vida de uma personagem mulher sem passar pelo momento de sua concepção e de sua gestação. É aí que reside a fórmula encontrada por Clarice Lispector.

A fórmula, que nesse caso denominar-se-á planta, necessitava de um desenho, baseado na ideia que o narrador de $A$ hora da estrela admite:

De uma coisa tenho certeza: essa narrativa mexerá com uma coisa delicada: a criação de uma pessoa interia que na certa está tão viva quanto eu. Cuidai dela porque meu poder é só mostrá-la para que os a reconheçais na rua, andando levemente por causa de sua esvoaçada magreza. ${ }^{6}$

Para tanto a escritora revela, no ato de criar, como ela arquiteta a narrativa e busca a sua gênese, ou até antes da gênese da personagem, ou seja, a palavra, "que é fruto da palavra". ${ }^{7}$

A partir da palavra todo um processo criativo é descrito para aproximar o leitor não só do personagem, mas do momento primeiro em que a escritora decide as linhas dessa construção e ela determina que a narrativa será criada com falso livre arbítrio - vai ter uns sete personagens e eu sou um dos mais importantes. Eu Rodrigo S. M. Relato antigo, este, pois não quero ser modernoso e inventar

\footnotetext{
${ }^{2}$ ROSSONI. Zen e a poética auto-reflexiva de Clarice Lispector, p. 215.

${ }^{3}$ LISPECTOR. A hora da Estrela, p. 14.

${ }^{4}$ LISPECTOR. A hora da Estrela, p. 19.

${ }^{5}$ ROSSONI. Zen e a poética auto-reflexiva de Clarice Lispector, p. 8.

${ }^{6}$ LISPECTOR. A hora da estrela , p. 18.

7 LISPECTOR. A hora da estrela, p. 18.
} 
modismos à guisa da originalidade (...) uma história com começo, meio e gran finale seguido de silêncio e chuva caindo. ${ }^{8}$

Esse esquema que demarca a origem do texto forma um contraponto com o final, quando o narrador diz: "O final foi bastante grandiloqüente para a nossa necessidade? Morrendo ela virou ar. Ar energético? Não sei. Morreu em um instante." ${ }^{\prime 9}$ O gran finale anunciado se concretiza pela ação da chuva. A chuva anunciada não ocorre, entretanto podemos observar a questão do instante como alternância entre duas posições, neste caso a gota de água, que hora caí e ora não no mesmo lugar.

"Na Índia, diz-se da mulher fecunda que ela é chuva, isto é, a fonte de toda prosperidade. ${ }^{10} \mathrm{E}$ o narrador de $A$ hora da estrela diz que, na hora que ela saiu da cartomante, "Macabéa ficou um pouco aturdida sem saber se atravessaria a rua pois sua vida já estava mudada. E mudada por palavras - desde Moisés se sabe que a palavra é divina. Até para atravessar a rua ela já era outra pessoa. Uma pessoa grávida de futuro. ${ }^{\prime 11} \mathrm{O}$ estar fecunda e a aproxima da chuva, que viria após o gran finale, e ao mesmo tempo a deixa num estado de consciência de si mesma. Ela pela primeira vez sonha com o futuro. E são as palavras que irão transformá-la. A palavra é a origem de tudo e move o texto, carregando, de forma monstruosa, a vida e a morte de Macabéa, pois em detalhes sua fisionomia e seus atos chegam aos sentidos do leitor como se fossem algo feio, disforme. Seu serviço é medíocre, contudo, ela é mais porque não consegue construir uma página de texto, sem erros ou factâncias. Perdida entre o trabalho e a casa miserável, o quarto, que divide com outras moças. Ela é sempre a última, até por perder o namorado para a outra colega de serviço, por esta ter uma casa, uma família, um pai com um emprego.

O próximo passo, nesta construção, após a instalação da palabra, é a escolha da voz de quem vai narrar. A escritora instaura uma voz, que a princípio tenta desvincular-se dela, mas obra e vida de Clarice Lispector se encontram no ato de criar. E por se encontrarem na origem desse plano cartesiano, "a obra lhe é um repositório da vida e a experiência de vida, ${ }^{12}$ que em $A$ hora da estrela a faz criar, viver e reviver experiências profundas que a levam a dividir-se para depois reunificar essas vozes com a consciência que a morte precede a vida e assim sucessivamente.

Se tudo é circular na obra de Clarice Lispector, pois ela tenta voltar à origem, a um tempo, no qual todas as coisas eram uma só, logo, os narradores, que são instaurados, na obra em análise, são vozes suas transfiguradas para que, de forma mais profunda, ela atinja o instante da criação e o depois.

Esses narradores são divididos em duas vozes e três níveis, segundo a terminologia utilizada por Gerard Genette (1979), que será adotada nesse estudo de $A$ hora da estrela. As vozes nesse estudo são heterodiegética e autodiegética, em níveis extradiegético, intradiegético e metadiegético. Antes de iniciar essas colocações são necessárias algumas explicações, entre elas a questão da diegese, a narração, que no caso dessa obra se subdivide em duas. Uma a do ato de criar e a

\footnotetext{
${ }^{8}$ LISPECTOR. A hora da estrela, p. 12.

${ }^{9}$ LISPECTOR. A hora da estrela, p. 73.

${ }^{10}$ CHEVALIER; GHEERBRANT. Dicionário de símbolos, p. 237.

${ }^{11}$ LISPECTOR. A hora da estrela, p. 67.

${ }^{12}$ ROSSONI. Zen e a poética auto-reflexiva de Clarice Lispector, p. 215.
} 
outra da vida da nordestina Macabéa. As vozes nesse romance são duas. Uma é a do narrador que relata os primeiros instantes antes de instituir o segundo narrador: "Enquanto eu tiver perguntas e não houver resposta continuarei a escrever." ${ }^{13}$ Escrever é um ato de tentar responder às inquietações que perturbam a escritora e que ela transporta para esse narrador heterodiegético, que relata as perguntas e as tentativas de respostas, que a obra pode lhe dar. Ao final essa voz conclui: "Meu Deus, só agora me lembrei que agente morre. Mas - mas eu também?!"14 A obra respondeu a questão das perguntas pertinentes à morte, que naquele ano de 1977 preocupavam a escritora. E a forma de demonstrar que essa voz como a outra que serão analisadas aqui são de Clarice Lispector é o tratamento em terceira pessoa e primeira que se alternam no decorrer da narração, num processo, que a princípio parece simples, contudo desenvolve-se um jogo entre a narradora Clarice e o narrador Rodrigo S. M., semelhante ao jogo entre detetive mal e detetive bom. Nem um dos dois pretende defender Macabéa, contudo confundem o leitor para revelar a apoteose monstruosa da morte da personagem. Todos os narradores matam de um jeito ou de outro seus personagens, ou simplesmente se eles permanecem vivos é somente para enclausurá-los nas páginas do livro. Macabéa não, pois as sua morte, que veremos a seguir, é detalhada de forma tão monstruosa, que ao chegar ao limite, reverte-se o processo para que ela brilhe como uma estrela, e possa sair livre das páginas do livro.

A segunda voz, a autodiegética, é instaurada, num segundo momento, quando o primeiro narrador esquematiza a obra e o narrador, nesse caso uma voz masculina, denominada Rodrigo S. M. Esse personagem e narrador convive com Macabéa desde antes de sua criação e explicita ao leitor a relação entre criador e criatura. Em determinado momento ele diz: "Escrevo portanto não por causa da nordestina mas por motivo grave de força maior, como se diz nos requerimentos oficiais, por força de lei." ${ }^{15}$ Lei essa ancestral ao próprio homem, lei essa que vem de dentro, da necessidade de criar não só um personagem, mas uma forma de encarar a vida. E é com essa personagem, que muitas vezes nasce da lama interior e o faz viver com ela uma relação de amor e ódio. Amor por se compadecer de sua incapacidade de se autoconhecer; ódio por essa criatura lhe causar indagações sobre a existência do narrador e a sua relação com a morte. Esse protagonista Rodrigo S. M. não só desenha a história de Macabéa como também conversa com o leitor a respeito do ato de criar e da própria personagem. É ele o criador, que tenta buscar a protomatéria da existência da personagem, na qual "o caos precede a própria formação do inconsciente ${ }^{1}{ }^{16}$ revelada na seguinte passagem:

Esqueci de dizer que era realmente de se espantar que para o corpo quase murcho de Macabéa tão vasto fosse o seu sopro de vida quase ilimitada e tão rico como o de uma donzela grávida, engravidada, por partenogênese; tinha sonhos esquizóides nos quais apareciam gigantescos animais antidiluvianos como se ela tivesse vivido em épocas as mais remotas desta terra sangrenta. ${ }^{17}$

\footnotetext{
${ }^{13}$ LISPECTOR. A hora da estrela, p. 11.

14 LISPECTOR. A hora da estrela, p. 73.

15 LISPECTOR. A hora da estrela, p. 16.

${ }^{16}$ CHEVALIER; GHEERBRANT. Dicionário de símbolos, p. 167.

17 LISPECTOR. A hora da estrela, p. 50.
} 
A voz heterodiegética indaga: "Como começar pelo início se as coisas acontecem antes de acontecer? Se antes da pré-pré-história já havia monstros apocalípticos? Se essa história não existe passará a existir. Pensar é um ato. Sentir é um fato. Os dois juntos - sou eu que escreve o que estou escrevendo." ${ }^{18}$ Essa indagação antecipa o tempo que está por ocorrer e une de forma circular começo e fim com o uso de dois prefixos pre-aliados à ideia de apocalipse. Ou seja, não há começo e fim, mas ambos se unem na origem de tudo. Naquele instante, em que a existência dos seres é uma e não há diferença entre o homem, um animal ou uma pedra.

Essas duas vozes figuram em três níveis: um deles é o extradiegético, nos momentos em que a voz narrativa heterodiegética diz como arquitetará a narrativa e diz que esse texto "Não se trata apenas de narrativa, é antes de tudo vida primária que respira, respira, respira"19 e é a partir dessa observação, nesse nível, que o primeiro narrador vai compondo um painel da personagem Macabéa e do narrador Rodrigo S. M. como se os visse de uma outra dimensão através de um microscópio, que ora os aproxima, ora os distancia. Em cada um desses movimentos ele procura o melhor ângulo para os analisar. Criatura e criador, no final, são compostos da mesma matéria, que se solidifica pela palavra catalisadora.

No outro nível, o intradiegético, de dentro da história, Rodrigo S. M. relata as dúvidas e incertezas quanto ao ato de criar e o quanto Macabéa suga as suas forças, pois, por causa dela, ele deixa de fazer sexo, de se barbear, apenas para tentar descrevê-la, e, mesmo assim, ela se nega a materializar-se em seu texto. Quanto algo vem à sua mente e que pode servir de material para tentar compor a personagem e sua vida simples, ele escreve entre parentes o termo "explosão". Essas explosões também podem ser vistas como etapas para que Macabéa percorra um caminho, que ela mesma não sabe qual é. E é este que a levará a existir no mundo da matéria.

O nível metadiegético discute com o leitor o ato de criação e como ele é uma força que arquiteta um ser, que nesse caso não é apenas criar alguém, mas atingir a anterioridade dessa criação e tentar antecipar a vida passando pela morte. E nesse nível a voz heterodiegética classifica a história como "exterior e explícita" ${ }^{20}$ e diz que essa narrativa contém um segredo "a começar por um dos títulos, Quanto ao futuro, que é precedido por um ponto final e seguido de outro ponto final. Não se trata de capricho meu - no final talvez se entenda a necessidade do delimitado", ${ }^{21}$ porque entre um ponto e outro está o instante em que "é aquele átimo de tempo em que o pneu do carro correndo em alta velocidade toca no chão e depois não toca", ${ }^{22}$ pois sendo tão ínfimo já não se distingue a olho nu esse milésimo de segundo, no qual vida e morte se encontram, representados ao final do texto com uma imagem surrealista que une morte e tempo de morangos, assim como as indagações da escritora sobre a morte unem-se às vozes dos narradores para tentar retroceder ao tempo do narrador.

\footnotetext{
18 LISPECTOR. A hora da estrela, p. 11.

19 LISPECTOR. A hora da estrela, p. 12.

20 LISPECTOR. A hora da estrela, p. 12.

${ }^{21}$ LISPECTOR. $A$ hora da estrela, p.12.

22 LISPECTOR. A hora da estrela, p.73.
} 
Este texto se encerra referindo-se ao que é a obra $A$ hora da estrela. 0 resultado parece simples, que muitas vezes o leitor não consegue observar as infinitas possibilidades de análise que o livro oferece, e muitas nuances passam despercebidas; outras são bem evidentes, como o nome das personagens: Rodrigo S. M., Macabéa, Olímpico, Glória e Carlota; uso de palavras no diminutivo por parte da cartomante e por fim a presença de animais.

Em relação a esses nomes, há de se observar o do narrador Rodrigo S. M., que Maria Lígia Guidin considera "como heterônimo de Clarice Lispector". ${ }^{23}$ Esse nome pode ser estudado de outra forma, pois ao indefinir seu sobrenome, apenas utilizando as iniciais, a autora retira dele o status de escritor, pois geralmente eles são conhecidos pelo sobrenome como Alencar, Machado de Assis, Lima Barreto, entre outros. No caso de Clarice Lispector, ela é conhecida por seu nome completo, logo o seu heterônimo precisa ser descaracterizado. Nisso ela difere de Fernando Pessoa, pois seus heterônimos tinham nome, sobrenome, biografias diferenciadas e formas individuais de escrever. Esse processo utilizado pela escritora favorece, ao final da construção da personagem Macabéa que ela se revele ao leitor, e Rodrigo deixe de ser o narrador, sem que o leitor perceba que a autora assumiu a voz narrativa.

O nome da personagem Macabéa, segundo ela, a mãe lhe "botou ele por promessa a Nossa Senhora da Boa Morte" ${ }^{\prime 24}$ se ela vingasse. Esse nome deriva de Macabeus, que está contido no Velho Testamento da Bíblia. Esse livro ou conjunto de livros, pois são quatro, narra a luta do povo judeu contra seus inimigos sírios, que queriam impor o culto a Zeus. O simbolismo do nome Macabéa fundamenta-se na tradição judaico-cristã, enquanto os nomes Olímpico e Glória têm estreita ligação com a tradição greco-romana. A oposição entre esses lados desse triângulo amoroso faz com que as linhas gregas se aproximem, pois Glória significa uma honraria, que para Olímpico era o seu ideal depois que ele descobre que ela tem uma família, alimentação regular, um pai açougueiro e, além disso, é carioca, pertencendo ao sul do Brasil e a melhor origem possível, que ele possa ter como companheira e como mãe de seus filhos. Macabéa, por sua vez, não tem atrativos e por isso ele a deixa. Enquanto os macabeus vencem a tradição helênica, em $A$ hora da estrela são os helênicos encabeçado por Olímpico, cujo nome lembra os ideais de perfeição grega, que vencem e se apaixonam.Os gregos vencem, punindo assim Macabéa pelo pecado ancestral de Helena e de Eva. Mas até qual ponto há uma similaridade, visto que Helena é a destruidora e Eva é a tentadora, enquanto Macabéa é a descrição da monstruosidade? Macabéa encerra os traços de uma nordestina, que lembra-nos de Os sertões de Euclides da Cunha, no qual o descrever o nordestino como um Quasimodo, até que em determinado momento, ele abre um parêntese ao dizer que eles são fortes, pois são descendentes dos bandeirantes, que por sua vez descendem dos portugueses. Remontando a origem dos portugueses atribuída a Vigo, um troiano, o crime cometido, merece o castigo hereditário, que persegue a personagem Macabéa.

O nome Carlota, a cartomante, parece comum para uma ex-prostituta e cafetina, mas nada é por acaso nos livros de Clarice Lispector e é nisso que consiste esta análise. Quando a personagem Macabéa vai visitar a cartomante, ela se

${ }^{23}$ GUIDIN. Roteiro de leitura: $A$ hora da estrela de Clarice Lispector, p. 68.

${ }^{24}$ LISPECTOR. A hora da estrela, p. 38. 
vislumbra com as cores e a textura das flores, do sofá e das paredes da casa de Carlota. O que até então era cinza passou a ter cores semelhante ao que ocorre com a personagem Ana do conto "Amor" da mesma autora. A visão é aguçada e ocorre ali um momento epifânico, no qual Macabéa vê o mundo com mais consistência e passa a desejar as coisas.

A cartomante a trata com diminutivos como "minha adoradinha". ${ }^{25}$ Esse eco lembra um som de assovio, sibilar como um som de serpente. Esse som reporta à ideia da sibilas, que eram "lendárias profetisas, das quais a mais célebre foi a troiana Cassandra. Dava-se a elas o nome de Pítia - relativo a à serpente píton". ${ }^{26}$ No caso de Cassandra, ela foi amaldiçoada para que suas previsões fossem falsas.

Dessas duas ideias a de que a sibila lembra serpente e da maldição de Cassandra é possível tirar duas ideias propostas sobre Carlota. A primeira se refere ao modo gentil como ela tratou Macabéa, em termos, a cativando tal qual a serpente de Gênesis, que iludiu Eva. Assim ela ilude Macabéa com promessas de que ela seria feliz e se casaria com um estrangeiro rico de nome Hans. A segunda é quanto às previsões de Cassandra, pois a cartomante Carlota prevê um futuro brilhante para Macabéa e diz ser sincera, pois ela pôs as cartas para uma cliente que saiu antes de Macabéa e disse "aquela moça, que saiu daqui que ela ia ser atropelada". 27 Quem acaba atropelada é Macabéa. As previsões de Carlota são trocadas e não se concretizam, tal qual ocorria com Cassandra.

A presença de bichos na obra de Clarice Lispector é uma constante, só que em $A$ hora da estrela, ela, na voz de seu heterônimo Rodrigo S. M., discute a sua preferência por animais em relação ao ser humano: "É. Eu me acostumo mas não amanso. Por Deus! Eu me dou melhor com os bichos do que com gente", ${ }^{28}$ pois para ela o cavalo é livre e solto, o cão não exige explicações, enquanto os homens têm que procurar uma resposta para tudo. Resposta, que fica oculta ao leitor, quando no conto "O cobrador" de Rubens Fonseca, o ladrão não quer mais o dinheiro, mas sim a destruição do casal, cortando a cabeça do homem e o ventre da mulher. Cabeça e ventre, dois ethos, na obra $A$ hora de estrela de Clarice, que consegue nos encantos da cartomante," fazer a cabeça" de Macabéa , ao ponto de ela sentir como se o seu ventre estivesse grávido de esperança.

A interposição de duas palavras de ínfima significância para o ser humano, o ventre(vida) e a cabeça (raciocínio), numa dimensão de (inter) relação, que as aproxima na descrição do acidente de Macabéa, quando o ventre retorcido e a cabeça batida contra o meio fio se tocam, pois seu corpo fica numa posição fetal, de início, de recomeço, de princípio, no qual toda a monstruosidade de uma vida , de um ser, de uma morte cede espaço para o novo, o reinício, não deixando um gosto amargo. O que assemelha o romance de Clarice com a tradição literária brasileira da impunidade quanto ao crime, fixa-se na impunidade, que percorre caminhos traçados por Machado, no qual o crime nunca é punido: assim Rita é morta pelo marido, em "A cartomante", Bentinho pune Capitu e o filho, mas não é punido, Rubião fica pobre e louco, mas Sophia e Palhares não são punidos. O não punir o crime, o crime como forma social, o crime enquanto condição do homem,

\footnotetext{
${ }^{25}$ LISPECTOR. A hora da estrela, p. 63.

${ }^{26}$ CHEVALIER; CHEERBRANT. Dicionário de símbolos, p. 832.

27 LISPECTOR. A hora da estrela, p.65.

${ }^{28}$ LISPECTOR. A hora da estrela, p. 28.
} 
percorre a obra de Rubem Fonseca, demonstrando como a cidade pode ser um ambiente fértil para as relação criminosas.

Procurar respostas utilizando a palavra para Clarice Lispector é um exercício constante de encontrar-se e encontrar a origem de todas as coisas. A arquitetura dessa nordestina é antes de tudo a planta que desenha linhas congruentes, que aproximam a vida e a obra dessa autora. Essa aproximação é um exercício do ato de escrever, que faz de Macabéa um mapa para ler sua obra, bem como toda uma tradição voltada para a criação de narradores (pluri) conscientes de sua força narrativa e de sua invencibilidade, enquanto formuladores de crimes, pecados e monstruosidades.

Abstract:

To design Macabéa as a narrative construct, Clarice Lispector had to go back to a moment before the creation act, to the light at the beginning of life. And to give life to a feminine character, without passing for the moment of its conception and its gestation. It is there that the formula used by Clarice Lispector can be found, because to look for answers is a constant exercise of meeting oneself and finding the origin of all things, then the architecture of this northeastern woman is before everything the blueprint that draws congruent lines that go toward the Brazilian literary tradition of the relation between crime, sin, and monstrosity, established by Machado de Assis.

Keywords: Tradition; symbols; crime

Referências

CHEVALIER, J.; GHEERBRANT, A. Dicionário de símbolos. Trad. Vera Costa e Silva. Rio de Janeiro: José Olympio, 2000.

GENETTE, G. O discurso da narrativa. Lisboa: Arcádia, 1979.

GUIDIN, M. L. Roteiro de leitura: A hora da estrela de Clarice Lispector. São Paulo: Ática, 1998.

LISPECTOR, C. A hora da estrela. Rio de Janeiro: Rocco, 1998.

ROSSONI, I. Zen e a poética auto-reflexiva de Clarice Lispector: uma literatura de vida e como vida. São Paulo: Ed. Unesp, 2002. 